\title{
Knowledge, Attitude and Practice of Patients towards Orthodontic Treatment: A Multi-centric Study
}

\author{
Dr Rabindra Man Shrestha, ${ }^{1}$ Dr Prakash Bhattarai, ${ }^{2}$ Dr Jyoti Dhakal, ${ }^{3}$ Dr Sujita Shrestha \\ 'Associate Professor, ${ }^{3}$ Lecturer, Dept of Orthodontics, ${ }^{4}$ Lecturer, Dept of Community \& \\ Public Health Dentistry, Kantipur Dental College, Kathmandu, Nepal \\ 2Professor, Dept of Orthodontics, Nepal Medical College, Kathmandu, Nepal
}

Correspondence: Dr Rabindra M Shrestha; email: rabindraortho@gmail.com

\section{ABSTRACT}

Introduction: Patient's perspective and cooperation on treatment procedure and service is very important to evaluate the management system and success of the orthodontic treatment.

Objective: To assess knowledge, attitude and practice of Nepalese patients towards orthodontic treatment and to find the difference of perception between female and male patients.

Materials \& Method: A structured questionnaire comprising of fifteen questions in three sections was used among 536 orthodontic patients at eight orthodontic treatment centers. The knowledge, attitude and practice were assessed on Likert scale. The data were rescored based on positive, neutral or negative perceptions and depicted for a level. The difference in perception between female and male patients was tested using Mann-Whitney $U$ test.

Result: $85 \%$ of orthodontic patients possess good knowledge about ongoing orthodontic treatment; however about half of the patients are unaware about retainers. About 35\% patients think that people wearing braces do not look good, $59 \%$ experience long waiting time, $25 \%$ feel time spent for procedure is inadequate and $68 \%$ believe orthodontic treatment is expensive; still $82 \%$ are happy about treatment outcome. Most of the patients brush and rinse more carefully, however $28.9 \%$ patients are careless about braces and $12.7 \%$ forget appointment dates.

Conclusion: Nepalese orthodontic patients possess good knowledge about orthodontic treatment, however lack adequate attitude and practice towards the treatment. The practitioners should inform patients about retainers and be concerned about waiting time, procedure duration and cost of the treatment.

Key words: knowledge, attitude, practice, fixed orthodontic appliance, orthodontic patients

\section{INTRODUCTION}

Social psychologists have described various theories on patient compliance. Many components of 'Health Belief Model' are applicable to orthodontic treatment situation. Variables like treatment-seeking behavior, personality type and barriers to action comply well with the compliance of the patient. ${ }^{1,2}$ A compliant orthodontic patient may be described as a patient who practices good oral hygiene, follows appropriate diet, maintains appliance without breaking, keeps regular appointments, and follows instructions of the doctor. The cooperation of the patient helps in achieving treatment goal more expeditiously. The compliant patient may be identified by personal and demographic characteristics such as; age, sex, personality type, social class etc. Since sex is an imperative attribute variable, it is frequently reported in many studies. ${ }^{3-6}$

The knowledge, attitude and practice (KAP) study explores changes in knowledge, attitude and practice of the target group with respect to predetermined domain. The KAP study serves as an assessment tool to measure information, perspective, and performance of any desired task of the community. It enables the efficient process of evaluation; which allows the procedure to be tailored appropriately to the needs of the society. ${ }^{7}$

Orthodontic treatment is highly technique-sensitive and timeconsuming ${ }^{8}$ clinical procedure. Patient's understanding in its technical aspect and compliance in appliance maintenance are important for management and successful outcome of the treatment. The purpose of the present study is to evaluate the current perspective of Nepalese orthodontic patients towards orthodontic treatment regardless of the practitioner and treatment center and to assess the difference of perceptions between female and male patients.

\section{MATERIALS AND METHOD}

The study was conducted after receiving permission from Institutional Review Committee. The study was conducted among 536 orthodontic patients, who have been undergoing orthodontic treatment using fixed appliance for at least six months duration. The patients with dentofacial deformities like cleft palate were excluded from the study. The study sample comprised of 348 female and 188 male subjects of the age range 12 to 30 years (mean 19.45 years). 
The study was conducted at various orthodontic treatment centers offering exclusive orthodontic service of qualified specialists; viz: Kantipur Dental College \& Hospital, People's Dental College \& Hospital, Kathmandu University School of Medical Sciences-Dhulikhel Hospital, Samaj Dental Hospital, Mero Dental Hospital, The Orthodontic Center, Dental Arch Clinic and Dental Square Clinic. The study was conducted during September 2013 - February 2014.

The study is based on structured questionnaire referring to Dental Attitude Questionnaire.9.10 The questionnaire was modified as per the Nepalese context. The questionnaire comprised of fifteen questions in three sections on knowledge, attitude and practice with five questions each. The reliability of the questionnaire was pretested on 50 samples.

The knowledge of the patients about orthodontic treatment was assessed on binary scale of agreement or disagreement. It comprised of five common facts related to orthodontic treatment, like: 'purpose of braces (K1)', 'treatment duration (K2)', 'importance of following instructions (K3)', 'consequences of incomplete treatment (K4)', and 'wearing of retainer (K5)'.

The attitude and practice sections were assessed on 3-point Likert scale. The attitude section comprised of five statements pertaining to patient's perspective on 'social aesthetics on braces wearers (A1)', 'waiting time (A2)', 'time spend for orthodontic procedure (A3)', 'satisfaction on treatment outcome (A4)', and 'cost of orthodontic treatment (A5)'. The practice section comprised of five desired performances on 'food restriction (P1)', 'oral hygiene maintenance (P2)', 'use of special cleaning aids (P3)', 'carefulness on appliance (P4)' and 'regular appointment (P5)' to maintain orthodontic appliance.

The self-administered questionnaire was written in English; questions were explained whenever required. The data were entered according to patient's perception on their agreement, disagreement, or neutral position. For knowledge component, items were rescored so that the positively formulated perception was scored land negatively formulated perception was scored 2. For Attitude and Practice components; positively formulated perception was rescored 1 , neutral perception was rescored 2 and negatively formulated perception was rescored 3. The scoring criteria and determination of level is depicted in Table 1. The difference in perception between female and male patients was tested using Mann-Whitney $U$ test. The level of significance was adjusted at 0.05 at $95 \%$ confidence interval. The data were analyzed using SPSS software version 17.0.

\section{RESULT}

The study found that, more than $85 \%$ of sample had knowledge on purpose of braces (K1) and treatment duration (K2). More than $90 \%$ had knowledge on importance of following instructions (K3), and consequences of incomplete treatment (K4). However, only $45.7 \%$ patients had the information on wearing of retainer after completing the orthodontic treatment (K5) (Table 2).

Table 1: Scoring criteria

\begin{tabular}{|l|c|c|c|c|c|c|}
\hline & Score & Level & Score & Level & \multicolumn{2}{|c|}{ Score } \\
\hline Knowledge & $1.0-1.50$ & Good & $1.51-2.0$ & Poor & \multicolumn{4}{|c|}{ Level } \\
\hline Attitude & $1.0-1.60$ & Good & $1.61-2.30$ & Moderate & $2.31-3.0$ & Poor \\
\hline Practice & $1.0-1.60$ & Good & $1.61-2.30$ & Moderate & $2.31-3.0$ & Poor \\
\hline
\end{tabular}

Table 2: Distribution of patients according to their knowledge of orthodontic treatment

\begin{tabular}{|c|c|c|c|c|c|c|c|}
\hline \multirow{2}{*}{\multicolumn{2}{|c|}{ Knowledge }} & \multicolumn{2}{|c|}{ Female $(\mathrm{N}=348)$} & \multicolumn{2}{|c|}{ Male $(\mathrm{N}=188)$} & \multicolumn{2}{|c|}{ Total $(\mathrm{N}=536)$} \\
\hline & & \multirow{2}{*}{$\begin{array}{c}n \\
295\end{array}$} & \multirow{2}{*}{$\begin{array}{c}\% \\
84.8\end{array}$} & \multirow{2}{*}{$\begin{array}{c}\mathrm{n} \\
162\end{array}$} & \multirow{2}{*}{$\begin{array}{c}\% \\
86.2\end{array}$} & \multirow{2}{*}{$\begin{array}{c}\text { n } \\
457\end{array}$} & \multirow{2}{*}{$\begin{array}{c}\% \\
85.3\end{array}$} \\
\hline $\mathrm{K} 1$ : Braces correct teeth and jaw & Agree (+) & & & & & & \\
\hline irregularities & Disagree(-) & 53 & 15.2 & 26 & 13.8 & 79 & 14.7 \\
\hline \multirow{2}{*}{$\begin{array}{l}\text { K2: Duration of orthodontic treatment } \\
\text { takes long time }\end{array}$} & Agree (+) & 288 & 82.8 & 171 & 91.0 & 459 & 85.6 \\
\hline & Disagree(-) & 60 & 17.2 & 17 & 9.0 & 77 & 14.4 \\
\hline \multirow{2}{*}{$\begin{array}{l}\text { K3: It is necessary to follow instructions } \\
\text { on oral hygiene and food habits }\end{array}$} & Agree (+) & 334 & 96.0 & 179 & 95.2 & 513 & 95.7 \\
\hline & Disagree(-) & 14 & 4.0 & 9 & 4.8 & 23 & 4.3 \\
\hline \multirow{2}{*}{$\begin{array}{l}\text { K4: If you leave the treatment } \\
\text { incomplete, the problem will worsen }\end{array}$} & Agree $(+)$ & 319 & 91.7 & 164 & 87.2 & 483 & 90.1 \\
\hline & Disagree(-) & 29 & 8.3 & 24 & 12.8 & 53 & 9.9 \\
\hline \multirow{2}{*}{$\begin{array}{l}\text { K5: You need to wear 'retainer' after } \\
\text { completion of the treatment }\end{array}$} & Agree (+) & 178 & 51.1 & 67 & 35.6 & 245 & 45.7 \\
\hline & Disagree(-) & 170 & 48.9 & 121 & 64.4 & 291 & 54.3 \\
\hline
\end{tabular}


The analysis on attitude of patients towards orthodontic treatment showed that; $49.3 \%$ patients had positive attitude towards social esthetics on braces wearers i.e. they disagree that people wearing braces do not look good (A1). $31.5 \%$ patients disagreed on long waiting time at waiting room (A2), $47.8 \%$ disagreed that time spend for orthodontic procedure during the appointment is inadequate (A3), and $82.2 \%$ patients are happy about treatment outcome so far (A4). $68.5 \%$ patients feel cost of orthodontic treatment is expensive (A5) (Table 3).

Table 3: Distribution of patients according to their attitude on orthodontic treatment

\begin{tabular}{|c|c|c|c|c|c|c|c|}
\hline \multirow{2}{*}{\multicolumn{2}{|c|}{ Attitude }} & \multicolumn{2}{|c|}{ Female $(\mathrm{N}=348)$} & \multicolumn{2}{|c|}{ Male $(\mathrm{N}=188)$} & \multicolumn{2}{|c|}{ Total $(\mathrm{N}=536)$} \\
\hline & & \multirow{2}{*}{$\begin{array}{c}\mathbf{n} \\
120\end{array}$} & \multirow{2}{*}{$\begin{array}{c}\% \\
34.5\end{array}$} & \multirow{2}{*}{$\begin{array}{c}\mathbf{n} \\
70\end{array}$} & \multirow{2}{*}{$\begin{array}{c}\% \\
37.2\end{array}$} & \multirow{2}{*}{$\begin{array}{c}\mathbf{n} \\
190\end{array}$} & \multirow{2}{*}{$\begin{array}{c}\% \\
35.4\end{array}$} \\
\hline \multirow{3}{*}{$\begin{array}{l}\text { A1: People wearing braces do not } \\
\text { look good }\end{array}$} & Agree (+) & & & & & & \\
\hline & Neutral $( \pm)$ & 47 & 13.5 & 35 & 18.6 & 82 & 15.3 \\
\hline & Disagree(-) & 181 & 52.0 & 83 & 44.2 & 264 & 49.3 \\
\hline \multirow{3}{*}{$\begin{array}{l}\text { A2: It is often very long time at waiting } \\
\text { room }\end{array}$} & Agree (+) & 200 & 57.47 & 116 & 61.7 & 316 & 59.0 \\
\hline & Neutral ( \pm ) & 35 & 10.06 & 16 & 8.51 & 51 & 9.5 \\
\hline & Disagree(-) & 113 & 32.47 & 56 & 29.79 & 169 & 31.5 \\
\hline \multirow{3}{*}{$\begin{array}{l}\text { A3: Time spend for orthodontic } \\
\text { procedure is too less }\end{array}$} & Agree (+) & 80 & 22.99 & 56 & 29.79 & 136 & 25.4 \\
\hline & Neutral $( \pm)$ & 97 & 27.87 & 47 & 25.0 & 44 & 26.9 \\
\hline & Disagree(-) & 171 & 49.14 & 85 & 45.21 & 256 & 47.8 \\
\hline \multirow{3}{*}{$\begin{array}{l}\text { A4: I am happy with the treatment } \\
\text { outcome so far }\end{array}$} & Agree (+) & 287 & 82.47 & 157 & 83.51 & 444 & 82.8 \\
\hline & Neutral ( \pm ) & 41 & 11.78 & 13 & 6.91 & 54 & 10.1 \\
\hline & Disagree(-) & 20 & 5.75 & 18 & 9.57 & 38 & 7.1 \\
\hline \multirow{3}{*}{$\begin{array}{l}\text { A5: Orthodontic treatment is } \\
\text { expensive }\end{array}$} & Agree (+) & 225 & 64.66 & 142 & 75.53 & 367 & 68.5 \\
\hline & Neutral ( \pm ) & 82 & 23.56 & 27 & 14.36 & 109 & 20.3 \\
\hline & Disagree(-) & 41 & 11.78 & 19 & 10.11 & 60 & 11.2 \\
\hline
\end{tabular}

Analysis on practice of patients showed that; $58.5 \%$ patients regularly restrict hard food and alter dietary habits (P1), $82.3 \%$ brush and rinse mouth more carefully (P2), and $39 \%$ use special cleaning aids (P3). Contrarily; $28.9 \%$ admit that brackets or wires usually break due to their carelessness (P4) and $12.7 \%$ often forget appointment dates (P5) (Table 4).

Table 4: Distribution of patients according to their practice on orthodontic treatment

\begin{tabular}{|c|c|c|c|c|c|c|c|}
\hline \multirow{2}{*}{\multicolumn{2}{|c|}{ Practice }} & \multicolumn{2}{|c|}{ Female $(\mathrm{N}=348)$} & \multicolumn{2}{|c|}{ Male $(\mathrm{N}=188)$} & \multicolumn{2}{|c|}{ Total $(\mathrm{N}=536)$} \\
\hline & & \multirow{2}{*}{$\begin{array}{c}n \\
200\end{array}$} & \multirow{2}{*}{$\begin{array}{c}\% \\
57.47\end{array}$} & \multirow{2}{*}{$\begin{array}{c}\mathbf{n} \\
115\end{array}$} & \multirow{2}{*}{$\begin{array}{c}\% \\
61.17 \\
\end{array}$} & \multirow{2}{*}{$\begin{array}{c}\mathbf{n} \\
315\end{array}$} & \multirow{2}{*}{$\begin{array}{c}\% \\
58.5\end{array}$} \\
\hline \multirow{3}{*}{$\begin{array}{l}\text { P1: Restrict food and alter dietary } \\
\text { habits to maintain braces }\end{array}$} & Yes (+) & & & & & & \\
\hline & Sometimes ( \pm ) & 113 & 32.47 & 53 & 28.19 & 166 & 31.0 \\
\hline & No (-) & 35 & 10.06 & 20 & 10.64 & 55 & 10.3 \\
\hline \multirow{3}{*}{$\begin{array}{l}\text { P2: Brush and rinse mouth more } \\
\text { carefully so that food does not stuck } \\
\text { in the braces }\end{array}$} & Yes (+) & 298 & 85.63 & 143 & 76.06 & 441 & 82.3 \\
\hline & Sometimes ( \pm ) & 43 & 12.35 & 29 & 15.42 & 72 & 13.4 \\
\hline & No (-) & 7 & 2.01 & 16 & 8.51 & 23 & 4.3 \\
\hline \multirow{3}{*}{$\begin{array}{l}\text { P3: Use special cleaning aids like } \\
\text { orthodontic brush, inter-dental brush, } \\
\text { mouthwash }\end{array}$} & Yes (+) & 139 & 39.94 & 70 & 37.23 & 209 & 39.0 \\
\hline & Sometimes ( \pm ) & 83 & 23.85 & 36 & 19.15 & 119 & 22.2 \\
\hline & No (-) & 126 & 36.21 & 82 & 43.62 & 208 & 38.8 \\
\hline \multirow{3}{*}{$\begin{array}{l}\text { P4: Brackets/wires often break due to } \\
\text { my carelessness }\end{array}$} & Yes (-) & 99 & 28.45 & 56 & 29.79 & 155 & 28.9 \\
\hline & Sometimes ( \pm ) & 105 & 30.17 & 65 & 34.57 & 170 & 31.7 \\
\hline & No $(+)$ & 144 & 41.38 & 67 & 35.64 & 211 & 39.4 \\
\hline \multirow{3}{*}{$\begin{array}{l}\text { P5: Often forget or miss regular ap- } \\
\text { pointment date }\end{array}$} & Yes (-) & 45 & 12.93 & 23 & 12.23 & 68 & 12.7 \\
\hline & Sometimes ( \pm ) & 99 & 28.45 & 62 & 32.98 & 161 & 30.0 \\
\hline & No $(+)$ & 204 & 58.62 & 103 & 54.79 & 307 & 57.3 \\
\hline
\end{tabular}

*positively formulated (+), neutral ( \pm ), negative (-) 
Table 5 portrays scoring of the knowledge, attitude and practice components and determination of level. Nepalese orthodontic patients possessed good level of all components of knowledge about orthodontic treatment except retainers. Knowledge on wearing of retainers was good among females but poor among male and total sample. The attitude of orthodontic patients on satisfaction on treatment outcome was good. Attitude on social aesthetics of braces wearers, time spend for orthodontic procedure and waiting time were moderate. The attitude of male patients about waiting time and attitude of all subjects on cost of orthodontic treatment were poor. The practice of orthodontic patients on food restriction, oral hygiene maintenance and regularity of appointment were good and practice on use of special cleaning aids and carefulness on appliance were moderate.

Table 5: Scoring and levels of Knowledge, Attitude \& Practice of Orthodontic patients

\begin{tabular}{|c|c|c|c|c|c|c|c|}
\hline & & \multicolumn{2}{|c|}{ Female } & \multicolumn{2}{|c|}{ Male } & \multicolumn{2}{|c|}{ Total } \\
\hline & & Score & Level & Score & Level & Score & Level \\
\hline \multirow{5}{*}{ 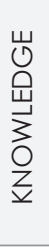 } & $\mathrm{K} 1$ : Purpose of braces & 1.15 & Good & 1.14 & Good & 1.15 & Good \\
\hline & K2: Treatment duration & 1.17 & Good & 1.09 & Good & 1.14 & Good \\
\hline & K3: Importance of following instructions & 1.04 & Good & 1.05 & Good & 1.04 & Good \\
\hline & K4: Consequence of incomplete treatment & 1.08 & Good & 1.13 & Good & 1.10 & Good \\
\hline & K5: Wearing of retainer & 1.49 & Good & 1.64 & Poor & 1.54 & Poor \\
\hline \multirow{5}{*}{$\begin{array}{l}\text { 㟧 } \\
\stackrel{E}{\rightleftarrows} \\
\stackrel{E}{<}\end{array}$} & A1: Social aesthetics on braces wearers & 1.82 & Moderate & 1.93 & Moderate & 1.86 & Moderate \\
\hline & A2: Waiting time & 2.25 & Moderate & 2.32 & Poor & 2.27 & Moderate \\
\hline & A3: Time spend for orthodontic procedure & 1.74 & Moderate & 1.85 & Moderate & 1.78 & Moderate \\
\hline & A4: Satisfaction on treatment outcome & 1.23 & Good & 1.26 & Good & 1.24 & Good \\
\hline & A5: Cost of orthodontic treatment & 2.53 & Poor & 2.65 & Poor & 2.57 & Poor \\
\hline \multirow{5}{*}{ 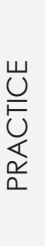 } & P1: Food restriction & 1.53 & Good & 1.49 & Good & 1.51 & Good \\
\hline & P2: Oral hygiene maintenance & 1.16 & Good & 1.32 & Good & 1.22 & Good \\
\hline & P3: Use of special cleaning aids & 1.96 & Moderate & 2.06 & Moderate & 2.00 & Moderate \\
\hline & P4: Carefulness on appliance & 1.87 & Moderate & 1.94 & Moderate & 1.90 & Moderate \\
\hline & P5: Regular appointment & 1.54 & Good & 1.57 & Good & 1.55 & Good \\
\hline
\end{tabular}

The statistical analysis showed significant difference between female and male patients on knowledge on duration of orthodontic treatment (K2) and wearing of retainers (K5), attitude on cost of orthodontic treatment (A5) and in practice of brush and rinse mouth more carefully (P2) (Table 6).

Table 6: Mann-Whitney U Test statistics to assess the difference between female and male subjects

\begin{tabular}{|c|c|c|c|c|c|c|c|c|}
\hline & & \multicolumn{2}{|c|}{ Total } & \multicolumn{2}{|c|}{ Female } & \multicolumn{2}{|c|}{ Male } & \multirow{2}{*}{$p$-Value } \\
\hline & & Mean & SD & Mean & SD & Mean & SD & \\
\hline \multirow{5}{*}{ KNOWLEDGE } & $\mathrm{K} 1$ & 1.15 & 0.355 & 1.15 & 0.36 & 1.14 & 0.34 & 0.663 \\
\hline & K2 & 1.14 & 0.351 & 1.17 & 0.37 & 1.09 & 0.28 & $0.010 *$ \\
\hline & K3 & 1.04 & 0.203 & 1.04 & 0.19 & 1.05 & 0.21 & 0.677 \\
\hline & K4 & 1.10 & 0.299 & 1.08 & 0.27 & 1.13 & 0.33 & 0.101 \\
\hline & K5 & 1.54 & 0.499 & 1.49 & 0.50 & 1.64 & 0.48 & $0.001 *$ \\
\hline \multirow{5}{*}{ ATTITUDE } & Al & 1.86 & 0.911 & 1.82 & 0.91 & 1.93 & 0.90 & 0.175 \\
\hline & A2 & 2.27 & 0.912 & 2.25 & 0.91 & 2.32 & 0.90 & 0.381 \\
\hline & A3 & 1.78 & 0.826 & 1.74 & 0.80 & 1.85 & 0.85 & 0.180 \\
\hline & A4 & 1.24 & 0.571 & 1.23 & 0.53 & 1.26 & 0.62 & 0.928 \\
\hline & A5 & 2.57 & 0.685 & 2.53 & 0.69 & 2.65 & 0.65 & $0.017^{*}$ \\
\hline \multirow{5}{*}{ PRACTICE } & $\mathrm{Pl}$ & 1.51 & 0.675 & 1.53 & 0.67 & 1.49 & 0.68 & 0.501 \\
\hline & P2 & 1.22 & 0.508 & 1.16 & 0.42 & 1.32 & 0.62 & $0.003^{*}$ \\
\hline & P3 & 2.00 & 0.883 & 1.96 & 0.87 & 2.06 & 0.89 & 0.206 \\
\hline & P4 & 1.90 & 0.820 & 1.87 & 0.82 & 1.94 & 0.80 & 0.320 \\
\hline & P5 & 1.55 & 0.708 & 1.54 & 0.71 & 1.57 & 0.70 & 0.510 \\
\hline
\end{tabular}

*Statistically significant at $p<0.05$ 


\section{DISCUSSION}

Egolf et $a^{11}$ studied factors like belief, attitude, perceptions, and reasons thought to be associated with compliance. They considered these factors as combination of personality type, negative motives (pain, inconvenience, dysfunction) and positive motives (health awareness, specific dental knowledge, personal oral embarrassment). A study by Bos et $\mathrm{al}^{12}$ however, did not find correlation between compliance and satisfaction among orthodontic patients. The present study assessed information of the patient on orthodontic treatment required for its compliance and maintenance. The assessment on attitude of the patient was related to perception on treatment service and cost, and questions on practice were related to oral hygiene methods and carefulness of the patient. The present study did not assess the barriers to action, as the questions were not targeted at the reasons for non-cooperation. The study also did not consider patient's pain perception and inconvenience due to braces. The study on pain experience during orthodontic treatment among Nepalese patients was analyzed by Kafle and Rajbhandari. ${ }^{13}$

Various studies identified female orthodontic patients as more cooperative than males. ${ }^{3-6}$ The present study showed similar finding in many parameters that female Nepalese patients possessed better understanding and perceptions towards ongoing orthodontic treatment.

Siddegowda and Rani ${ }^{14}$ found moderate level of knowledge and awareness about orthodontist and irregular teeth, and less awareness about orthodontic treatment among Indian school children through an epidemiological survey. Bos et al found significantly positive attitude towards orthodontists in previously treated subjects compared to untreated ones. The orthodontically treated subjects' attitude towards the satisfaction with treatment result and experiences with follow-up appointments were good. ${ }^{10}$ It is assumed that the general public have positive attitude towards orthodontic profession; ${ }^{15,16}$ parents who were former orthodontic patients are more likely to approve their child for orthodontic treatment. ${ }^{17,18}$

It is satisfactory to learn that Nepalese orthodontic patients possess good level of knowledge about orthodontic treatment. However, only $45.7 \%$ patients had the information about wearing of retainer. This fact would lead to difficulty in prescribing the retainers after the treatment and jeopardize the stability of results. The practice of orthodontic patients on oral hygiene, food restriction, and regularity of appointment were good; however use of special cleaning aids was moderate. The present report on oral hygiene maintenance of Nepalese orthodontic patients is consistent with the previous study on same population. ${ }^{19}$

These information are pertinent for better clinical management for service providers. It can help improve their service and enhance rapport with the patients. Actually, orthodontist's interpersonal behavior and role in patient motivation is another aspect of successful orthodontic treatment. The orthodontist should give positive feedback and communicate with the patient on the issues of patient cooperation and their inconveniences. Orthodontists should explain about the appliance including retainers, and advice on oral hygiene, dietary control and appliance maintenance methods. Patients who are dissatisfied with the treatment and interpersonal aspects tend to avoid care and jeopardize the name, and fame of the orthodontic practice and the practitioner.

\section{CONCLUSION}

Nepalese orthodontic patients possess good level of knowledge about orthodontic treatment, but had poor information about the retainers. About half the number of patient thinks that wearing the braces do not look good, however more than $80 \%$ patients are happy about the treatment outcome. In general, the attitude of orthodontic patients towards ongoing orthodontic treatment is moderate, and two third of the patients think that orthodontic treatment is expensive. Although the orthodontic patients practice good oral hygiene, food restriction and regular appointment; they are only moderately careful about the appliance breakage.

Despite having good knowledge on orthodontic treatment, patient's attitude and practice towards orthodontic treatment is mostly moderate. It is important for practicing orthodontists to inform patients about the retainers, appliance maintenance and build inter-personal rapport with the patients. The practitioners shall improve the patient attitude by shortening the waiting time of patients at waiting room, adequately spend time on procedure and charge the treatment cost more reasonably.

\section{ACKNOWLEDGEMENT}

We would like to thank Dr Anjana Rajbhandari, Dr Dashrath Kafle, Dr Manish Bajracharya for their cooperation in data collection and all orthodontic patients who participated in the study. 


\section{REFERENCES}

1. Haynes RB, Taylor DW, Sackett DL, eds. Compliance in health care. Baltimore: Johns Hopkins University Press, 1979. Am. J. Orthod. Dentofac. Orthop. April 1990

2. Tulloch JFC, Shaw WC, Underhill BDS, Smith A, Jones G, Jones M. A comparison of attitudes toward orthodontic treatment in British and American communities. Am J Orthod 1984; 85:253-9

3. Kreit LH, Burstone C, Delman L. Patient cooperation in orthodontic treatment. J Am Coll Dent 1968;35:327-32.

4. Gravely JF. A study of need and demand for orthodontic treatment in two contrasting National Health Service Regions. Br J Orthod 1990 17:287-292.

5. Gray M, Anderson R. A study of young people's perception of their orthodontic treatment need and their experience of orthodontic services. Primary Dent Care 1998; 5:87-93.

6. Stambach HK, Kaplan A. Profile of an excellent orthodontic patient. Angle Orthod 1975;45:141-

7. Kaliyaperumal K.. Guideline for conducting a Knowledge, Attitude and Practice (KAP) study. Comm Ophthal $2004 ; 4: 1$.

8. Bhattarai P, Shrestha RM. Comparative study of duration of orthodontic treatment among Nepalese adolescent and adult patients. Orthod J Nep201 1; 1:1:28-30.

9. Bos A, Hoogstraten J, Prahl-Andersen B. A comparison of dental health care attitudes in the Netherlands in 1985,1995 and 2001 . Comm Dent Oral Epidemio 2003; 31:207-212.

10. Bos A, Hoogstraten J, Prahl-Andersen B. Attitudes toward orthodontic treatment: a comparison of treated and untreated subjects. Eur J Orthod 2005; 27:148-54.

11. Egolf R, BeGole EA, Upshaw HS. Factors associated with orthodontic patient compliance with intraoral elastic and headgear wear. Am J Orthod Dentofac Orthop. 1990; 97:336-48

12. Bos A, Vosseiman N, Hoogstraten J, Prahl-Anderson B. Patient compliance: A determinant of patient satisfaction? Angle Orthod 2005: 75:526-31.

13. Kafle D, Rajbhandari A. Anticipated Pain and Pain Experience among Orthodontic Patients: Is there any Difference? Kathmandu UniV Med J 2012; 38(2):71- 73.

14. Siddegowda R, Rani. MS. An epidemiological survey on awareness towards orthodontic treatment in South Indian school children. Open J Dent Oral Med. 2013;1 (1):5-8.

15. Tulloch JFC, Shaw W, Smith A. A comparison of attitudes toward orthodontic treatment in British and American communities. Am J Orthod 1984; 85:253-9.

16. Richardson ME. The layman's view of orthodontics: A literary review. Br Dent J 1998; 185:324-7.

17. Pietilä T, Pietilä I. Parents' views on their own child's dentition compared with an orthodontist's assessment. Eur J Orthod 1994; 16:309-16.

18. Pratelli P, Gelbier S, Gibbons DE. Parental perceptions and attitudes on orthodontic care. Br J Orthod 1998; 25:41-6.

19. Shrestha S, Shrestha L, Shrestha N, Shrestha RM. Effect of orthodontic treatment in occurrence of dental caries. Orthod J Nep 2013; $3(1): 31-36$ 